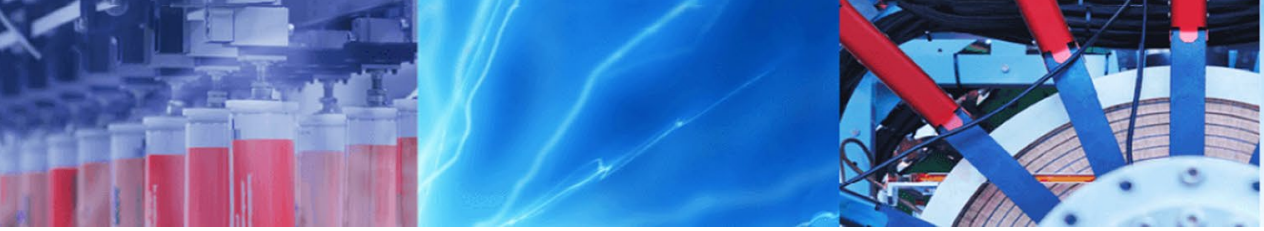

Research Article

\title{
$5 \%$ Barium doped zinc oxide semiconductor nanoparticles for the photocatalytic degradation of Linezolid: synthesis and characterisation
}

\author{
V. S. Bhamare ${ }^{1}$ (D) R. M. Kulkarni ${ }^{1} \cdot$ B. Santhakumari ${ }^{2}$
}

C) Springer Nature Switzerland AG 2018

\begin{abstract}
Undoped zinc oxide nano-particles (ZONPs) and 5\% (mole ratio) barium doped zinc oxide nano-particles (BZONPs) were synthesized by chemical precipitation method. These semiconducting materials were used for the photocatalytic degradation of antibacterial drug Linezolid (LNZ) for the $\mathrm{pH}$ ranging from 4.0 to 8.0. X-ray diffraction (XRD) patterns show that the intensity of peak is slightly stronger in ZONPs than in 5\% (mole ratio) BZONPs. The calculated average grain size using Scherrer equation for ZONPs and 5\% (mole ratio) BZONPs are found to be $35.08( \pm 3) \mathrm{nm}$ and $24.39( \pm 2) \mathrm{nm}$ respectively. Scanning Electron Microscopy images show that both semiconductor materials are uniform and homogeneous with closely aggregate oval in shape. Energy dispersive X-ray spectroscopy (EDX) of $5 \%$ (mole ratio) BZONPs shows that the mass percentage of zinc is 71.2 , oxygen is 23.9 and barium is 4.78. The influences of different parameters on the photocatalytic degradation of LNZ were investigated thoroughly. The rate of photocatalytic degradation of LNZ was increased first from 0.05 to $0.1 \mathrm{~g} / \mathrm{L}$ dosage of photocatalyst but after that the rate decreases with increase of dosage of photocatalyst. The kinetic data reveals that there was initial increase in the rate of reaction with increase in the [LNZ]. The effect of $\mathrm{pH}$ indicates that there is increase in the rate of reaction from $\mathrm{pH} 4.0$ to 8.0.The rate of degree of mineralization of LNZ is found higher at the higher light intensities of UV lamp.
\end{abstract}

Keywords Semiconductor materials . Photocatalysis - Barium doped zinc oxide nanoparticles - Water treatment . Linezolid

\section{Introduction}

It has been reported by various research studies that toxic organic contaminants which are found in environmental waters have detrimental effects on human beings and animals. A detail and organized investigation is must to comprehend the transport, occurrence and fate of toxic organic contaminants in environmental waters. There is basic and immediate requirement to retain drinking water resources clean, innocuous and safe [1, 2].

There are various oxidation techniques reported in the literature to eliminate toxic organic contaminants present in environmental waters [3]. The conventional method of chlorination is used to kill the germs present in drinking water but it also produces harmful side products during the water treatment process [4]. Heptavalent manganese (HVMG) is used as an oxidant and disinfectant during water treatment process due to its ability to oxidize the toxic organic contaminants [5]. HVMG gives unpleasant colour to the treated drinking water. This is a major drawback of this oxidant in the process of water treatment [6-8]. These traditional methods are not very effective to eliminate toxic organic contaminants [9].

$\triangle$ V.S. Bhamare, vbhamare37@gmail.com | 'Department of Chemistry, KLS Gogte Institute of Technology (Autonomous) Affiliated to Visvesvaraya Technological University, Belagavi, Karnataka 590 008, India. ${ }^{2}$ Center for Materials Characterization Division, CSIR-National Chemical Laboratory, Pune, Maharashtra 411008, India.

SN Applied Sciences (2019) 1:103 | https://doi.org/10.1007/s42452-018-0114-8 
Literature study reveals that various transition metals are widely used for homogeneous catalysis to eliminate toxic organic contaminants. There are many drawbacks of homogenous catalysis such as high cost, difficult recovery, poor thermal stability and single active sites of transition metal catalyst as reported in previous studies [6]. In order to overcome these drawbacks, heterogeneous catalysis is used during water treatment process [10]. Advanced oxidation processes (AOPs) are considered as very potent and innovative methods for eliminating the toxic organic contaminants present in environmental waters [11, 12]. Semiconductor materials such as pristine $\mathrm{ZnO}$ and anatase $\mathrm{TiO}_{2}$ are used in AOPs under the UV or sunlight illumination for the photocatalytic degradation of toxic organic contaminants during water treatment process [13].

The semiconductor material $\mathrm{ZnO}$ is having higher exciton binding energy ( $60 \mathrm{meV}$ ). Zinc oxide nanoparticles (ZONPs) is a better photo-catalyst over anatase $\mathrm{TiO}_{2}$ nanoparticles for the degradation of toxic organic contaminants due its stability, wide band gap ( $3.3 \mathrm{eV})$, low-cost and better efficiency. Literature study reveals that ZONPs displays better results for the photo-degradation of toxic organic contaminants in acidic, neutral and basic reaction conditions while $\mathrm{TiO}_{2}$ nanoparticles are effective in acidic reaction conditions $[14,15]$.

ZONPs can be doped with various transition metals to reduce the particle size of nanoparticles and decline the rate of electron-hole recombination in this semiconductor material. Doping of transition metals involved in AOPs mainly focus on activating the semiconductor material ZONPs under UV or visible light to generate reactive species. These highly reactive species $\left(\mathrm{HO}_{2}, \mathrm{HO} \cdot\right)$ degrades the toxic organic contaminants under the UV or visible light $[16,17]$.

Doping transition metals into the structure of ZONPs change electronic structure of semiconductor which improves the optical, electrical and magnetic properties. Doping also improves photoreaction and photocatalytic activity of semiconductor materials. Doped semiconductor materials induce widening of wavelength from UV to visible light. Doped nano-sized materials facilitate interfacial electron transfer process at the surface of the photocatalyst which increases the surface reactivity $[18,19]$. Doped ZONPs have low band gap energy than undoped ZONPs [20]. Doping technique increases the number of surface defects in doped ZONPs than undoped ZONPs which enhances the photocatalytic degradation of toxic organic contaminants present in environmental waters [21].

Linezolid (LNZ) was the first antibacterial agent approved for the clinical use. It was found very effective against the specific severe infections caused by bacteria. Moreover, LNZ is also prescribed by the doctors for the viral infection in patients. LNZ is a better antibacterial agent for the human beings irrespective of their age. It is also secure antibacterial agent for the treatment in patients having kidney and liver related diseases [22]. The pKa value of antibacterial drug LNZ is 1.80 . Hence, it shows weak basic properties. LNZ is slightly soluble in water having $\mathrm{pH}$ values from 5.0 to 9.0 [23-25].

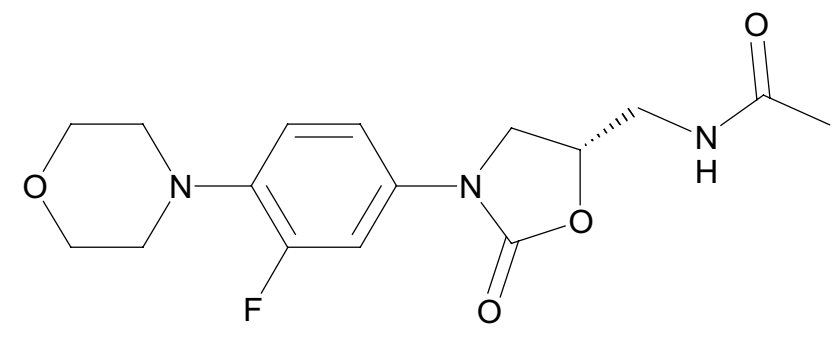

Chemical structure of Linezolid $\mathrm{C}_{16} \mathrm{H}_{20} \mathrm{FN}_{3} \mathrm{O}_{4}$

Literature study reveals that there are no reports found on the investigation of photo-catalytic degradation of antibacterial drug LNZ moiety by semiconductor material barium doped zinc oxide nano-particles (BZONPs) as a photocatalyst. In the current investigation, ZONPs and BZONPs were prepared by chemical precipitation method and characterized by different techniques. The rates of photocatalytic degradation of LNZ were determined to examine the efficiency of the BZONPs as a photocatalyst. The present study also includes the effects of different parameters on the rate of photocatalytic degradation of LNZ moiety. The various photo-degraded products formed during the photocatalytic degradation of antibacterial drug LNZ moiety using semiconducting materials are identified and a suitable mechanism is projected.

\section{Experimental}

\subsection{Chemical reagents and methods}

The different analytical reagents such as $\mathrm{Zn}\left(\mathrm{NO}_{3}\right)_{2} \cdot 4 \mathrm{H}_{2} \mathrm{O}$, $\mathrm{NaOH}$ and $\mathrm{BaNO}_{3}$ were purchased from the HIMEDIA to prepare semiconductor materials ZONPs and BZONPs by chemical precipitation method for the photo-degradation of antibacterial drug LNZ. Antibacterial drug Linezolid was obtained from Sigma Aldrich to prepare stock solutions of different concentrations for the photo-degradation study. The different buffers includes acetate buffer $(\mathrm{pH} 4.0-5.0)$, phosphate buffer $(\mathrm{pH} 6.0-7.0)$ and borate buffer $(\mathrm{pH}$ 8.0-9.0) of suitable concentrations were mixed in the reaction mixtures during photocatalytic study of LNZ to maintain a fixed $\mathrm{pH}$ and to provide a constant ionic strength. 


\subsection{Instruments}

(1) Kinetic investigation of photo-degradation of antibacterial drug LNZ moiety was performed using CARY 50 Bio UV-VIS Spectrophotometer (Varian BV, The Netherlands) with temperature controller and HPLC system (Shimadzu Prominence).

(2) Surfaces of semiconductor materials ZONPs and BZONPs are activated and illuminated under UV light (Light intensity $=4 \mathrm{~mW} \mathrm{~cm}^{-2}$ ) which was mounted inside the UV cabinet (Mercury lamp, PHILIPS, TUV $8 \mathrm{WT} 5, \mathrm{E}_{\max }=254 \mathrm{~nm}$ ) to produce highly reactive species $\left(\mathrm{HO}_{2}\right.$, $\left.\mathrm{HO} \cdot\right)$ for the photocatalytic degradation of antibacterial drug LNZ.

(3) During the photo-catalytic degradation process the intensity of UV light used for the activation of surfaces of ZONPs and BZONPs was measured using an optical power meter (Newport 2936-C) while pH of reaction mixtures was measured using sensitive Elico $\mathrm{pH}$ meter (models LI 120).

(4) The Particle size of prepared semiconductor materials ZONPs and BZONPs were calculated using Siemens X-ray Diffractometer (Cu source) (XRD) AXS D5005.

(5) The surface Topography of prepared semiconductor materials ZONPs and BZONPs was examined using a Scanning electron microscope (SEM) JEOL JSM 6360.

(6) Transmission electron microscopy (TEM) JEOL JEM2010 was used to understand the particle size and morphology of prepared semiconductor materials ZONPs and BZONPs.

\subsection{Preparation of photocatalysts}

Photocatalysts semiconductor materials ZONPs and BZONPs were prepared by chemical precipitation method in the laboratory. $100 \mathrm{ml} \mathrm{Zn(}\left(\mathrm{NO}_{3}\right)_{2} \cdot 4 \mathrm{H}_{2} \mathrm{O}$ solution of suitable concentration $\left(0.1 \mathrm{~mol} \mathrm{dm}^{-3}\right)$ and $100 \mathrm{ml}$ $\mathrm{NaOH}$ solution $\left(0.2 \mathrm{~mol} \mathrm{dm}^{-3}\right)$ were prepared in deionized water separately. A beaker of capacity $500 \mathrm{ml}$ was placed on a magnetic stirrer. $100 \mathrm{ml} \mathrm{Zn}\left(\mathrm{NO}_{3}\right)_{2} \cdot 4 \mathrm{H}_{2} \mathrm{O}$ aqueous solution was poured into the beaker properly. $10 \mathrm{mg} / \mathrm{L}$ of sodium dodecyl sulphate was added into $\mathrm{Zn}\left(\mathrm{NO}_{3}\right)_{2} \cdot 4 \mathrm{H}_{2} \mathrm{O}$ aqueous solution as a capping agent [26] to control particle size of $\mathrm{Zn}(\mathrm{OH})_{2}$ particles which would be formed into the beaker after the addition of $100 \mathrm{ml}$ basic aqueous solution of $\mathrm{NaOH}\left(0.2 \mathrm{~mol} \mathrm{dm}^{-3}\right)$ drop by drop using burette with continuous stirring (2000 RPM). This produces the crystals of zinc hydroxide in the beaker. This reaction mixture was stirred for a period of $5 \mathrm{~h}$. Then, the resultant mixture was not disturbed for a period of $10 \mathrm{~h}$. Then, the supernant part of this reaction mixture was discarded carefully to separate a white precipitate of $\mathrm{Zn}(\mathrm{OH})_{2}$. Deionized water and ethanol were used for washing a white precipitate to treat the impurities adhered to nanoparticles. Then washed nanoparticles were centrifuged. After washing and centrifugation, slurry of $\mathrm{Zn}(\mathrm{OH})_{2}$ placed in an oven to dry it at the temperature $120^{\circ} \mathrm{C}$ for a period of $4 \mathrm{~h}$. The dried $\mathrm{Zn}(\mathrm{OH})_{2}$ was grounded in a mortar properly. This grounded material was calcined at the temperature $500{ }^{\circ} \mathrm{C}$ in a muffle furnace (Heating rate is $10{ }^{\circ} \mathrm{C}$ per minute) for a period of $2 \mathrm{~h}$. At this temperature of $500{ }^{\circ} \mathrm{C}, \mathrm{Zn}(\mathrm{OH})_{2}$ gets converted into semiconductor material ZONPs. Similarly, semiconductor material 5\% (mole ratio) BZONPs were prepared in the laboratory by a chemical precipitation method. The only difference in preparing doped $5 \%$ (mole ratio) BZONPs was that of addition of $0.05 \mathrm{~mol} \mathrm{dm}^{-3} \mathrm{Ba}\left(\mathrm{NO}_{3}\right)_{2}$ aqueous solution into $0.1 \mathrm{~mol} \mathrm{dm} \mathrm{m}^{-3}$ of $\mathrm{Zn}\left(\mathrm{NO}_{3}\right)_{2} \cdot 4 \mathrm{H}_{2} \mathrm{O}$ aqueous solution to enter barium metal into the interstitial positions of semiconductor material ZONPs. The same experimental procedure was followed $[27,28]$.

\subsection{The photocatalytic degradation process}

In order to study the photocatalytic degradation of antibacterial drug LNZ, a required amount of LNZ and suitable buffer solutions were poured into a Pyrex beaker. Then, a dose of $0.10 \mathrm{~g} \mathrm{dm}^{-3}$ of semiconductor ZONPs was added into this reaction mixture and placed it undisturbed for a period of $3 \mathrm{~h}$ before the illumination of surfaces of nanoparticles by UV lamp to establish equilibrium of adsorption and desorption between the semiconductor material and antibacterial drug LNZ. This reaction mixture was placed on a magnetic stirrer with continuous stirring inside the UV cabinet mounted with UV lamp of $8 \mathrm{~W}$ (Philips) having wavelength peak at $254 \mathrm{~nm}$ and light intensity of 4 $\mathrm{mW} \mathrm{cm} \mathrm{cm}^{-2}$. During the degradation process under UV illumination, a small amount of degraded solution was taken out after every $10 \mathrm{~min}$ and kept for centrifugation at $5000 \mathrm{rpm}$ for $5 \mathrm{~min}$. A small amount of this centrifuged degraded mixture was taken into a cuvette to record its absorbance at $267 \mathrm{~nm}$ by using UV-Visible spectrophotometer for the kinetic investigation of photocatalytic degradation of antibacterial agent LNZ moiety. Similarly, the same experimental procedure is followed to investigate the degree of mineralization of LNZ moiety using another semiconductor material 5\% (mole ratio) BZONPs under UV illumination. The application of Lambert-Beers law was verified for [LNZ] at maximum wavelength $252 \mathrm{~nm}$ $\left(\varepsilon=32620 \mathrm{dm}^{3} \mathrm{~mol}^{-1} \mathrm{~cm}^{-1}\right)$. Pseudo first order rate constant values were calculated from the plot of log absorbance versus time. The completion of degradation reaction of LNZ moiety by $5 \%$ (mole ratio) BZONPs was checked by HR-MS instrument. 


\section{Results and discussion}

\subsection{Comparison of UV, UV/ZONPs and UV/5\% (mole ratio) BZONPs treatments}

The values of absorbance were recorded by UV-Vis spectrophotometer to calculate the values of rate constant for the photocatalytic degradation of antibacterial drug LNZ moiety using different photocatalyst such as UV, UV/ ZONPs and UV/5\% (mole ratio) BZONPs. The kinetic data obtained from UV-Vis spectrophotometer reveals that the photocatalytic activity of photocatalyst UV/5\% (mole ratio) BZONPs is better as compared to UV and UV/ZONPs for the degradation of antibacterial drug LNZ moiety (Fig. 1).

The influence of various \% of barium doping on the photocatalytic degradation of antibacterial drug LNZ under UV illumination was studied. The kinetic data reveals that the rate constants are higher in 5\% (mole ratio) BZONPs than $1 \%$ and $2 \%$ (mole ratio) BZONPs. This may due to decrease in particle size of 5\% (mole ratio) BZONPs than $1 \%$ and $2 \%$ (mole ratio) BZONPs. This increases the surface reactivity of semiconductor material $5 \%$ (mole ratio) BZONPs as compared to $1 \%$ and $2 \%$ (mole ratio) BZONPs. As a result of this, $5 \%$ (mole ratio) BZONPs increases the surface charge transfer and hinder the rate of recombination of photo-generated electron and hole. This increases the photocatalytic activity of 5\% (mole ratio) BZONPs for the photocatalytic degradation of antibacterial drug LNZ moiety under UV illumination [29]. It is also observed that the increase in $\%$ of doping beyond $5 \%$ in semiconducting material decreases the rate of degree of mineralization of LNZ present in environmental waters.

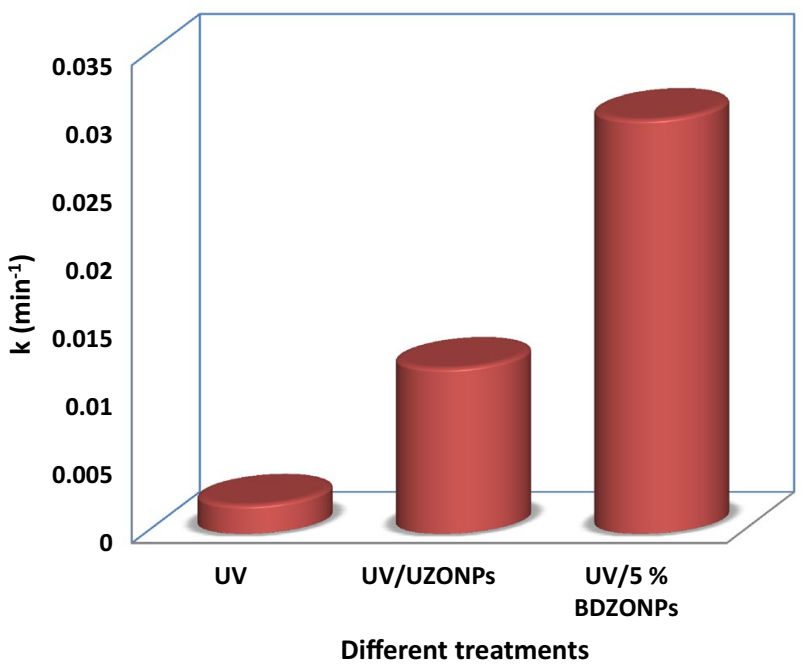

Fig. 1 Rate constants for the photocatalytic degradation of LNZ by various treatments
This may due to the accumulation of barium on the surface of doped semiconductor material and not entering inside the crystal lattice. Henceforth, the further study was carried out by using semiconductor material 5\% (mole ratio) BZONPs.

\subsection{Characterization of semiconductor material ZONPs and 5\% (mole ratio) BZONPs}

\subsubsection{X-ray diffraction (XRD) studies}

The XRD pattern (Fig. 2) of semiconducting materials ZONPs and $5 \%$ (mole ratio) BZONPs was obtained with the help of Siemens X-ray Diffractometer (Cu source) AXS D5005 to find out the particle size and phase purity. The XRD pattern of ZONPs and 5\% (mole ratio) BZONPs revealed that these semiconducting materials have hexagonal wurzite structure. XRD patterns show that the intensity of peak is slightly stronger in ZONPs than in 5\% (mole ratio) BZONPs. Barium metal is bigger in size than zinc. It is observed from the XRD patterns that peaks of $5 \%$ (mole ratio) BZONPs slightly shifted towards the lower angles than ZONPs. This shifting of peaks takes place due to difference in ionic radii of $\mathrm{Zn}^{2+}=0.088 \mathrm{~nm}$ and $\mathrm{Ba}^{2+}=0.135 \mathrm{~nm}$ and shows a lattice distortion of the crystal lattice. After analyzing XDR patterns, Line broadening is observed in $5 \% \mathrm{Ba}$ doped $\mathrm{ZnO}$ indicating $\mathrm{Ba}$ atoms have entered the crystal structure of $\mathrm{ZnO}$ and possibly occupying interstitial position as their sizes are bigger than Zn. [30]. XRD pattern of ZONPs and $5 \%$ (mole ratio) BZONPs shows that there is no impurity peak observed which confirms the proper doping and decorating with $5 \%$ (mole ratio) barium metal in the lattice structure of doped ZONPs.

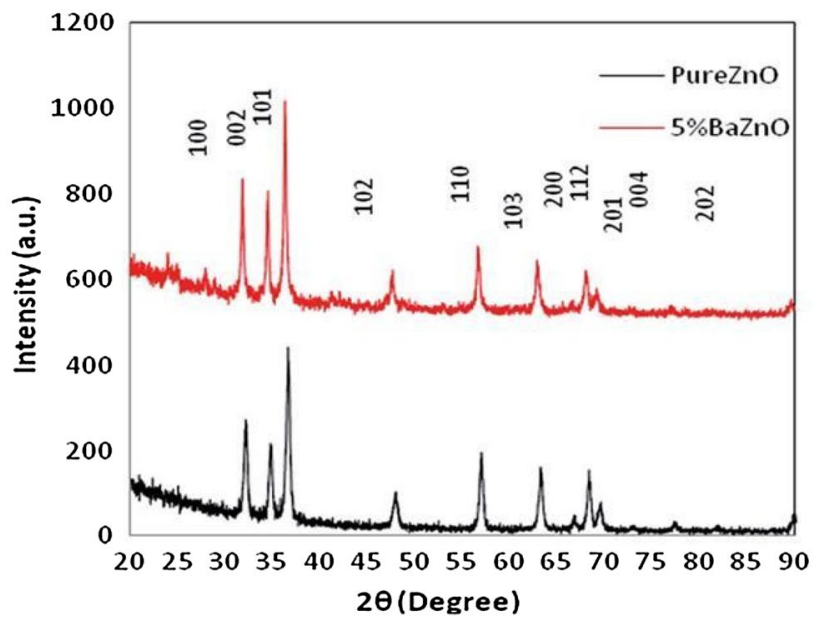

Fig. 2 XRD patterns of semiconducting material ZONPs and 5\% (mole ratio) BZONPs 
Scherrer equation was used to evaluate the particle size of ZONPs and 5\% (mole ratio) BZONPs semiconducting materials from the broadening of wurzite main intense peak (101) [31].

\section{$D=k \lambda / \beta \cos \theta$}

After putting the values of different terms involved in above Scherrer equation such as $\boldsymbol{k}$. denotes the dimensionless shape factor (0.94), $\beta$ denotes the full width at half-maximum (WDHM), D denotes average crystalline diameter, $\boldsymbol{\lambda}$ denotes $\mathrm{X}$-ray wavelength in angstrom $\left(0.154 \times 10^{-9} \mathrm{~m}\right)$ and $\boldsymbol{\theta}$ denotes Bragg diffraction angle; average crystallite size of ZONPs and $5 \%$ (mole ratio) BZONPs were found to be $35.2( \pm 3) \mathrm{nm}$ and $24.5( \pm 2) \mathrm{nm}$ respectively. These calculated values of average crystallite size are in agreement with literature ( $10 \mathrm{~nm}$ to $40 \mathrm{~nm})$. The barium cation attracts oxygen anion towards it and hence reduces the crystalline size of $5 \%$ (mole ratio) BZONPs than undoped ZONPs. This can be attributed to the fact that as the size of $5 \%$ (mole ratio) BZONPs decreases, the rate of photocatalytic degradation of LNZ increases due to increase in surface area of 5\% (mole ratio) BZONPs [11]. 5\% (mole ratio) BZONPs facilitate interfacial electron transfer process at the surface of the photocatalyst which increases the surface reactivity $[18,19]$.

\subsubsection{Scanning electron microscope (SEM) for photocatalysts}

JEOL JSM 6360 SEM was used to study morphologies of prepared semiconducting materials ZONPs and $5 \%$ (mole ratio) BZONPs. The precision distance (1 micro meter length) and voltage ( $20 \mathrm{kv}$ ) were adjusted to get magnified image of semiconducting materials ZONPs and 5\% (mole ratio) BZONPs. SEM images as presented in Fig. 3a, b for ZONPs and $5 \%$ (mole ratio) BZONPs show that these semiconducting materials are uniform and homogeneous with tightly aggregate oval in shape. Analysis of SEM images shows slightly increase surface area in $5 \%$ (mole ratio) BZONPs. Hence the rate of degree of mineralization of LNZ by $5 \%$ (mole ratio) BZONPs is more than ZONPs under UV illumination.

\subsubsection{Energy dispersive X-ray (EDX) spectroscopy for photocatalysts}

EDX JEOL JED-2300 was used to perform quantitative element analysis for semiconducting materials ZONPs and $5 \%$ (mole ratio) BZONPs photocatalyst. EDX of ZONPs shows two peaks while EDX of $5 \%$ BZONPs shows three peaks. The Peaks at 8.630, 0.252 and $4.464 \mathrm{k} \mathrm{eV}$ in EDX of ZONPs and $5 \%$ BZONPs reveal the presence of zinc, oxygen and barium respectively. This proves that there are only three
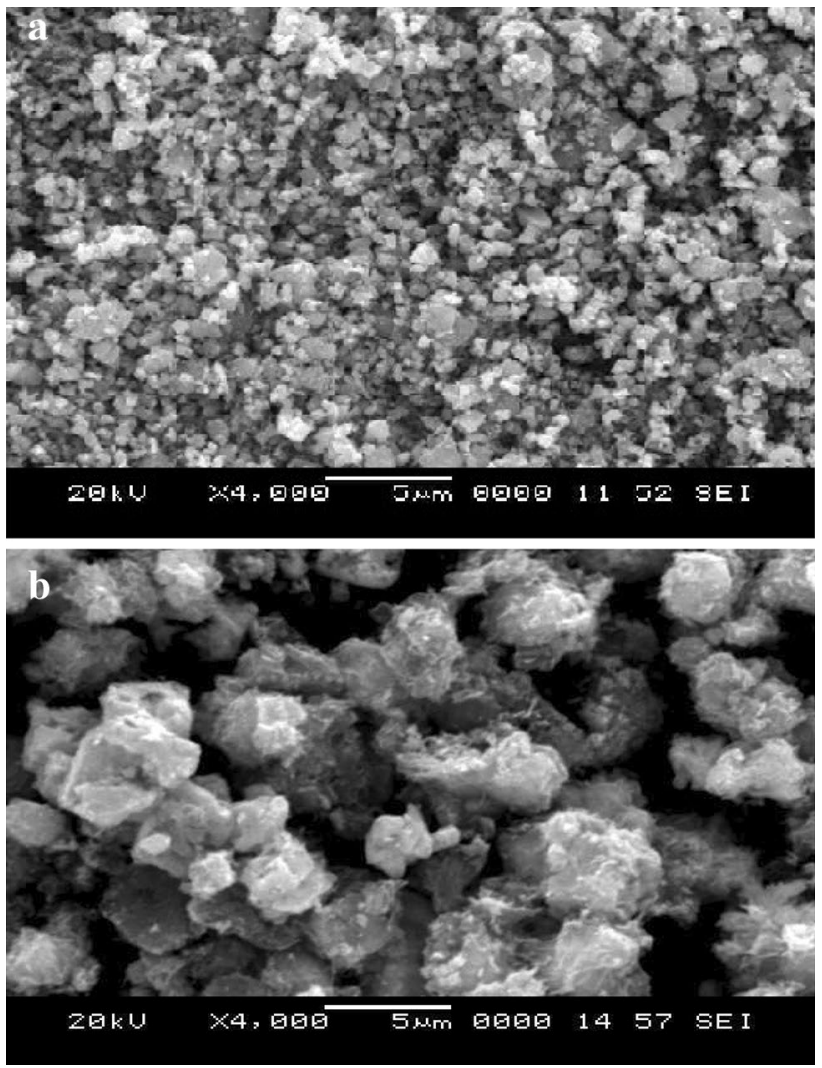

Fig. 3 a SEM Micrographs of semiconducting material ZONPs. b SEM Micrographs of semiconducting material 5\% (mole ratio) BZONPS

elements ( $\mathrm{Zn}, \mathrm{Ba}$ and $\mathrm{O})$ are present in the semiconducting materials. No additional peak in EDX of ZONPs and $5 \%$ BZONPs are observed which confirms that no impurity is present in semiconducting materials. The calculated atomic percentages of zinc, oxygen and barium elements from EDX data are 41.6, 57.1 and $1.33 \%$ respectively. The mass $\%$ for zinc, oxygen and barium elements obtained from EDX data are $71.26,23.95$ and 4.78 respectively. This quantitative analysis confirms that $4.78 \%$ barium is present in the crystal lattice of $5 \%$ (mole ratio) BZONPs which is an efficient photocatalyst for the photocatalytic degradation of LNZ.

\subsubsection{Transmission electron microscope (TEM) for photocatalysts}

The particle size and morphology of semiconducting materials ZONPs and 5\% (mole ratio) BZONPs were analyzed with the help of TEM JEOL JEM-2010 which shows 5\% (mole ratio) BZONPs semiconducting materials are agglomerated with non-uniformly distributed having barrel shaped crystalline structures (Fig. 4a, b).TEM micrographs of $5 \%$ (mole ratio) BZONPs shows a dispersion of 

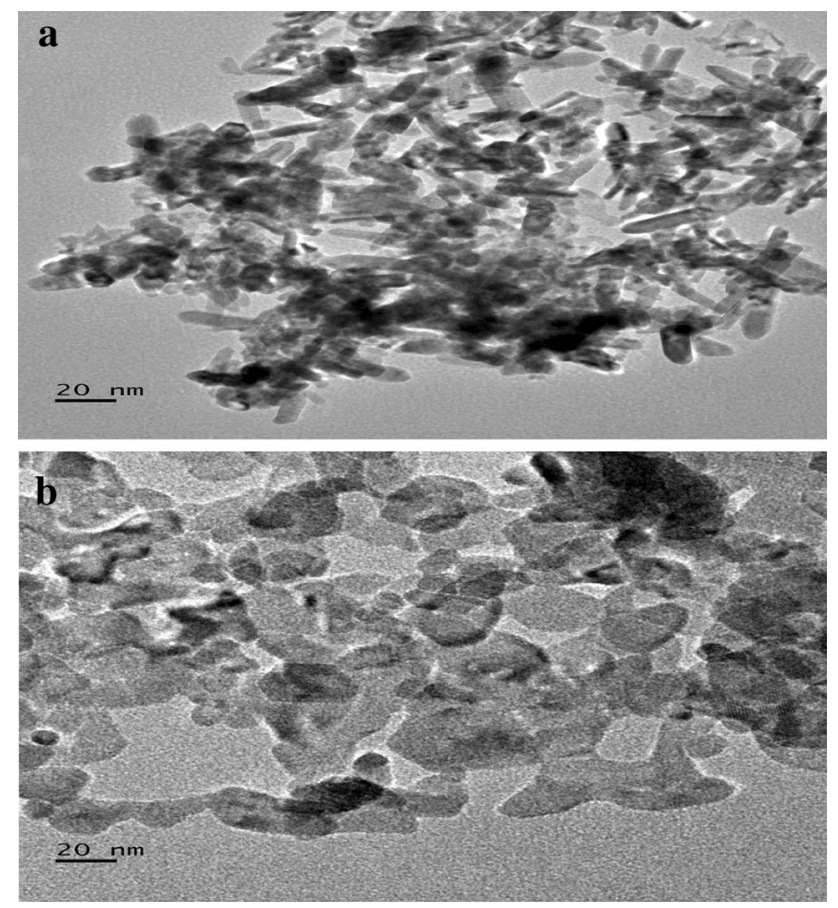

Fig. 4 a TEM micrographs of semiconducting material ZONPs. b TEM micrographs of semiconducting material $5 \%$ (mole ratio) BZONPS

small black spots which confirms the presence of barium atoms in the crystal lattice of ZONPs with approximately $15-20 \mathrm{~nm}$ and $25-30 \mathrm{~nm}$ in width and length dimension respectively. These crystal dimensions of semiconducting materials obtained from TEM are found closer to the dimensions obtained from XRD.

\subsection{Influence of loading of semiconducting materials on the reaction rate}

The rate of mineralization of LNZ was investigated by adding different amounts of semiconducting material $5 \%$ (mole ratio) BZONP ranging from 0.05 to $0.250 \mathrm{~g} \mathrm{dm}^{-3}$ into the reaction mixture kept in a photo-reactor at fixed $[\mathrm{LNZ}]$ and $\mathrm{pH}=8$. The kinetic data reveals that the rate of mineralization of LNZ increases by loading the semiconducting material 5\% (mole ratio) BZONP ranging from 0.05 to $0.1 \mathrm{~g} \mathrm{dm}^{-3}$ into the reaction mixture which may be due to increase in surface area of semiconducting material 5\% (mole ratio) BZONP and hence it increases the active centers on the semiconducting material $5 \%$ (mole ratio) BZONP. This generates higher number of hydroxyl radicals which enhances the rate of mineralization of $L N Z$. But beyond this limiting value of $0.1 \mathrm{~g} \mathrm{dm}^{-3}$ of semiconducting material $5 \%$ (mole ratio) BZONP, the rate of mineralization of LNZ decreases due to increase in turbidity of the LNZ suspension which hinders UV-light to reach the surface of the semiconducting material [28]. The plots of rate constant $\left(\mathrm{min}^{-1}\right)$ versus loading of the semiconducting materials ZONPs and 5\% (mole ratio) BZONP are presented in Fig. 5 and listed in Table 1.

\subsection{Influence of substrate concentration on reaction rates}

The rate of mineralization of substrate antibacterial drug LNZ moiety was investigated by changing the [LNZ] from $5.0 \times 10^{-6}$ to $5.0 \times 10^{-5} \mathrm{~mol} \mathrm{dm}^{-3}$ at fixed amount of ZNOPs $=0.1 \mathrm{~g} \mathrm{dm}^{-3}, 5 \%$ (mole ratio) BZONPs $=0.1 \mathrm{~g} \mathrm{dm}^{-3}$ and $\mathrm{pH}=8$. The absorbance of reaction mixture placed in UV cabinet was recorded with the help of spectrophotometer at different concentration of LNZ. The experimental data reveals that the rate of mineralization of antibacterial drug LNZ moiety increases initially till the $[L N Z]=3.0 \times 10^{-5} \mathrm{~mol} \mathrm{dm}^{-3}$ (Fig. 6, Table 2). This increase in rate constants may be due to excitation of higher number of LNZ drug molecules which are then adsorbed on

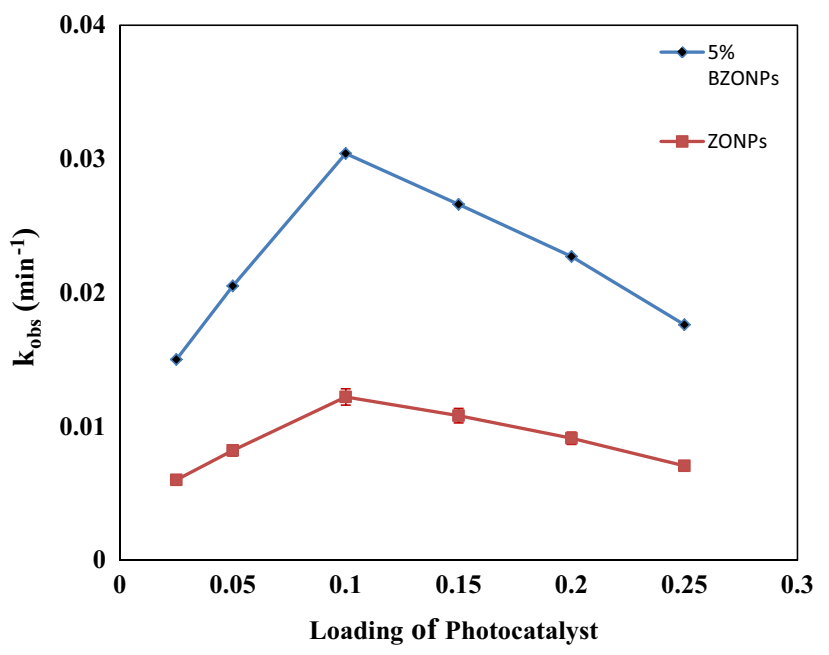

Fig. 5 Influence of loading of different quantities of semiconducting material ZONPs and 5\% (mole ratio) BZONPs at $[\mathrm{LNZ}]=3 \times 10^{-5} \mathrm{~mol} \mathrm{dm}^{-3}$ and $\mathrm{pH}=8$

Table 1 Influence of loading of different quantities of semiconducting material ZONPs and 5\% (mole ratio) BZONPs at $[\mathrm{LNZ}]=3 \times 10^{-5} \mathrm{~mol} \mathrm{dm}^{-3}$ and $\mathrm{pH}=8$

\begin{tabular}{lll}
\hline $\begin{array}{l}\text { ZONPs or } 5 \% \\
\text { [BZONPs] } \mathrm{gm}^{-3}\end{array}$ & $\begin{array}{l}\mathrm{k}_{\text {obs }} \times 10^{3}\left(\mathrm{~min}^{-1}\right) \\
\text { with ZONPs }\end{array}$ & $\begin{array}{l}\mathrm{k}_{\text {obs }} \times 10^{2}\left(\mathrm{~min}^{-1}\right) \text { with } \\
5 \% \text { (mole ratio) BZONPs }\end{array}$ \\
\hline 0.025 & 6.00 & 1.50 \\
0.050 & 8.20 & 2.05 \\
0.100 & 12.20 & 3.04 \\
0.150 & 10.80 & 2.66 \\
0.200 & 9.11 & 2.27 \\
0.250 & 7.05 & 1.76 \\
\hline
\end{tabular}




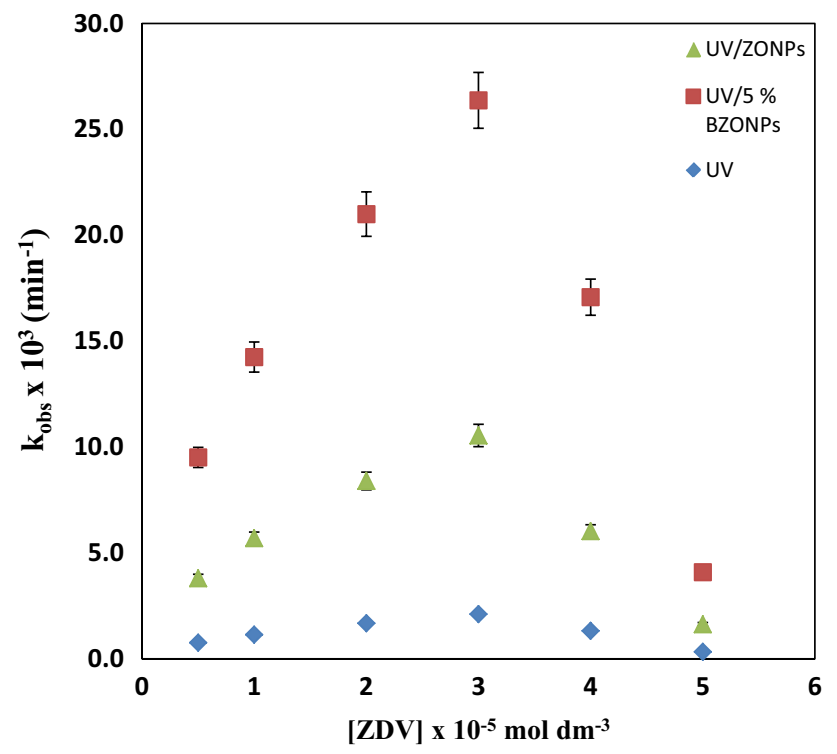

Fig. 6 Influence of variation in [LNZ] from $5 \times 10^{-6}$ to $5 \times 10^{-5}$ mol $\mathrm{dm}^{-3}$ on the rate of photo degradation of LNZ by UV, UV/ ZONPs and UV/5\% (mole ratio) BZONPs at [ZONPs] $=0.1 \mathrm{~g} \mathrm{dm}^{-3}$, $\left[5 \%\right.$ BZONPs] $=0.1 \mathrm{~g} \mathrm{dm}^{-3}$ and $\mathrm{pH}=8$

Table 2 Influence of variation in [LNZ] from $5 \times 10^{-6}$ to $5 \times 10^{-5} \mathrm{~mol} \mathrm{dm}^{-3}$ on the rate of photo degradation of LNZ by UV, UV/ZONPs and UV/5\% (mole ratio) BZONPs at [ZONPs] $=0.1 \mathrm{~g} \mathrm{dm}^{-3}$, $[5 \%$ BZONPs $]=0.1 \mathrm{~g} \mathrm{dm}^{-3}$ and $\mathrm{pH}=8$

\begin{tabular}{llll}
\hline$[\mathrm{LNZ}] \times 10^{5}$ & $\begin{array}{l}\mathrm{k}_{\mathrm{obs}} \times 10^{3} \\
\left(\mathrm{~min}^{-1}\right) \text { with } \\
\mathrm{UV}\end{array}$ & $\begin{array}{l}\mathrm{k}_{\mathrm{obs}} \times 10^{3} \\
\left(\mathrm{~min}^{-1}\right) \text { with } \\
\text { ZONPs }\end{array}$ & $\begin{array}{l}\mathrm{k}_{\mathrm{obs}} \times 10^{3}\left(\mathrm{~min}^{-1}\right) \text { with } \\
5 \%(\mathrm{~mole} \mathrm{ratio}) \text { BZONPs }\end{array}$ \\
\hline 0.5 & 0.76 & 3.80 & 9.51 \\
1.0 & 1.14 & 5.70 & 14.25 \\
2.0 & 1.68 & 8.40 & 21.00 \\
3.0 & 2.11 & 10.55 & 26.37 \\
4.0 & 1.32 & 6.03 & 17.08 \\
5.0 & 0.32 & 1.63 & 4.09 \\
\hline
\end{tabular}

the active centers of semiconducting material surfaces. It is also very interesting to note that after the limiting value of $[\mathrm{LNZ}]=3.00 \times 10^{-5} \mathrm{~mol} \mathrm{dm}^{-3}$, the organic substrate LNZ itself acts as a filter for the UV radiations. As a result of this, the photons can't reach the surface of semiconducting material and hence the rate of mineralization of LNZ declines [32, 33].

\subsection{Influence of varying $\mathrm{pH}$ on the mineralization of LNZ}

The $\mathrm{pH}$ of the photo-degradation reaction usually affects the adsorption capacity of the semiconductor adsorbent in aqueous medium. This is due to the modification in the surface properties of the semiconductor adsorbent. The influence of varying $\mathrm{pH}$ in the range of 4.0-8.0 was investigated thoroughly under the UV illumination by maintaining other reaction conditions fixed and recorded the absorbance using UV-Vis spectrophotometer. The plot of $\mathrm{k}_{\mathrm{obs}}\left(\mathrm{min}^{-1}\right)$ versus $\mathrm{pH}$ was presented in Fig. 7. The experimental data obtained from spectrophotometer indicates that the rate of mineralization of LNZ is lower at the acidic $\mathrm{pH}(4.0-6.0)$ and higher at the alkaline $\mathrm{pH}(8.0)$ of the reaction mixture under UV illumination. The reason behind the increase in rate of mineralization of LNZ moiety may be due to increase in higher number of $\mathrm{OH}^{-}$ions at alkaline $\mathrm{pH}=8.0$ which are responsible for the formation of more number of reactive hydroxyl radicals by combining with holes. It means that 5\% (mole ratio) BZONPs confirms higher degree of mineralization of LNZ moiety under UV illumination at slightly higher alkaline $\mathrm{pH}$ of reaction mixture, smaller particle size and more crystallanity of semiconducting material.

\subsection{Influence of light intensity on the rate of mineralization of LNZ}

The distance of UV lamp from the reaction mixture placed in a photo-reactor was varied to investigate the influence of light intensity on the rate of mineralization of LNZ using semiconductor materials. The kinetic data reveals that the rate of mineralization of LNZ increases with increase in light intensity. The reason behind this increase in rate of the reaction may be due to increase in photons striking per unit area of semiconducting material $5 \%$ (mole ratio) BZONPs. This enhances the number of photo-generated electron-hole pairs. The number of holes degrades the

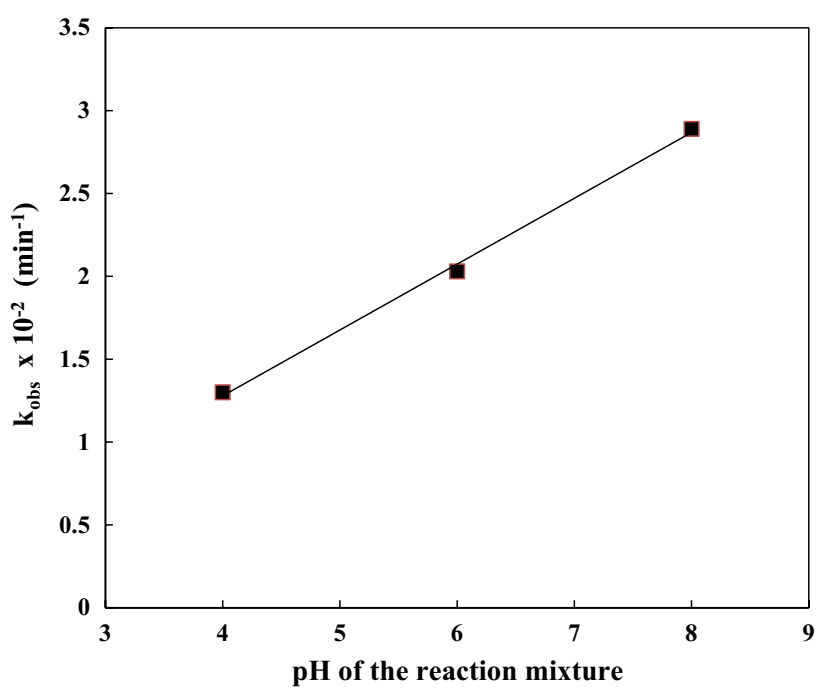

Fig. 7 Influence of varying $\mathrm{pH}$ on the rate of mineralization of LNZ using $5 \%$ (mole ratio) BZONPs at fixed [5\% BZONPs] $=0.1 \mathrm{~g} \mathrm{dm}^{-3}$ and $\left[\right.$ LNZ] $=3.0 \times 10^{-5} \mathrm{~mol} \mathrm{dm}^{-3}$ 
LNZ moiety adsorbed on the surface of semiconducting material 5\% (mole ratio) BZONPs into simple substances [34]. Hence, the rate of mineralization of LNZ using 5\% (mole ratio) BZONPs increases with increase in light intensity inside the UV photo-reactor at fixed $\mathrm{pH}$ of the reaction mixture (Fig. 8).

\subsection{The photo-generated electron hole pair mechanism}

Propan-2-ol as a scavenger of powerful ${ }^{\circ} \mathrm{OH}$ species or potassium iodide as a quencher of $\mathrm{h}^{+}$and ${ }^{\circ} \mathrm{OH}$ were mixed with substrate LNZ to check the mechanism and photocatalytic activity of semiconducting material $5 \%$ (mole ratio) BZONPs. The experimental data shows that $h^{+}$are reactive species in proposed mechanism of mineralization of LNZ using 5\% (mole ratio) BZONPs. Hence, it is supposed that after the adsorption of LNZ moiety on semiconducting material 5\% (mole ratio) BZONPs at dark, the mineralization of LNZ moiety under UV illumination takes place through direct reactions of LNZ moiety with $\mathrm{h}^{+}$which is trapped on the semiconducting material.

The analysis and identification of the photo-degraded products of LNZ moiety under UV illumination was performed by HR-MS using positive mode electro spray ionization $\left(\mathrm{ESI}^{+}\right)$. The mass spectra obtained from HR-MS for pure antibacterial drug LNZ moiety without UV and degradation products of LNZ under UV illumination are shown in Fig. 9. The photo-degradation products of LNZ under UV illumination are listed in Table 3 in the range $100-800 \mathrm{~m} / \mathrm{z}$. The structures of photo-degradation products of LNZ under UV illumination are shown in Fig. 10. The photo-generated

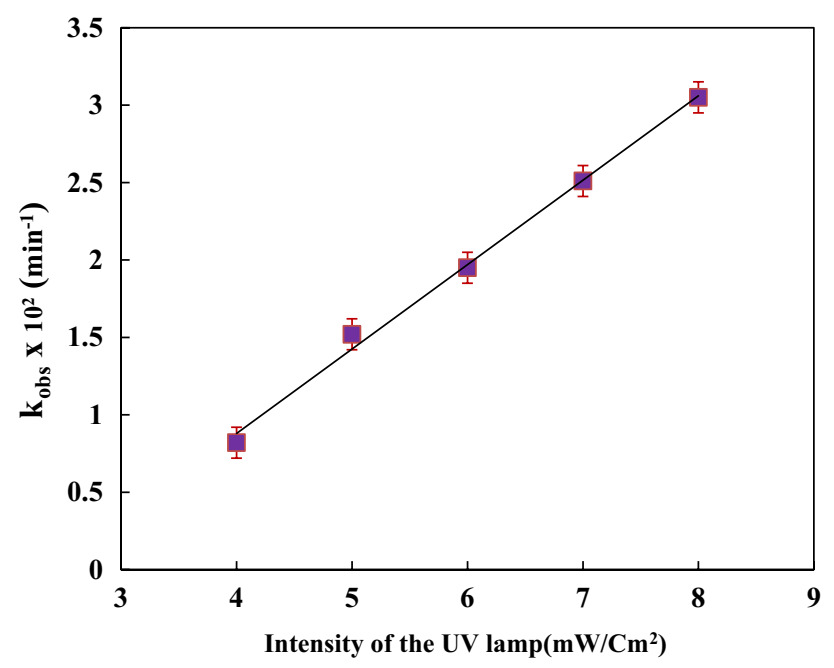

Fig. 8 Influence of variation in light intensity of UV lamp on the rate of mineralization of LNZ using 5\% (mole ratio) BZONPs at fixed $\left[5 \%\right.$ BZONPs] $=0.1 \mathrm{~g} \mathrm{dm}^{-3}$ and $[\mathrm{LNZ}]=3.0 \times 10^{-5} \mathrm{~mol} \mathrm{dm}^{-3}$ electron hole pair mechanism is proposed in Fig. 11 for the mineralization of LNZ moiety using 5 (mole ratio) \% BZONPs under UV illumination in agreement with the experimental results and HR-MS data.

Electron-hole pairs are generated at the surfaces of semiconducting material 5\% (mole ratio) BZONPs under UV illumination of suitable wavelength [35]. Most of these photo-generated electron-hole pairs undergo wasteful recombination while remaining photo-generated electron-hole pairs takes part in redox reactions to degrade the adsorbed antibacterial drug LNZ moiety on the surface of semiconducting material $5 \%$ (mole ratio) BZONPs under UV illumination. This photo-degradation using semiconductor material takes place due to higher values of redox potentials of photo generated excitons [12].

$5 \%$ BZONPs $+\mathrm{hv} \rightarrow 5 \%$ BZONPs $\left(\mathrm{h}^{+}+\mathrm{e}^{-}\right)$

The photo-generated holes ( $5 \%$ BZONPs) $\mathrm{h}^{+}$of the valence band as shown in above equation interacts with the water molecules and generates very reactive hydroxyl free radical species ( $(\mathrm{OH})$.

(5\% BZONPs) $\mathrm{h}^{+}+\mathrm{H}_{2} \mathrm{O} \rightarrow \mathrm{H}^{+}+\cdot \mathrm{OH}$

The photo-generated (5\% BZONPs) $\mathrm{h}^{+}$may also interact with $\mathrm{OH}^{-}$species to generate the highly reactive ${ }^{\circ} \mathrm{OH}$ species at the valence band of semiconducting material.

$(5 \%$ BZONPs $) \mathrm{h}^{+}+\mathrm{OH}^{-} \rightarrow \cdot \mathrm{OH}$

The hydroxyl reactive species ( $(\mathrm{OH})$ at the valence band of the $5 \%$ (mole ratio) BZONPs interacts with the adsorbed antibacterial drug LNZ moiety to mineralize harmful drug molecules into harmless simple substances.

$\mathrm{LNZ}+\mathrm{OH} \rightarrow$ Degraded products

The interaction between 5\% (mole ratio) BZONPs with $\mathrm{O}_{2}$ molecules produces super oxide radical anions $\left({ }^{\circ} \mathrm{O}_{2}{ }^{-}\right)$ at the conduction band of the semiconducting material under UV illumination. The reason behind this generation of ${ }^{\circ} \mathrm{O}_{2}{ }^{-}$may be due to transfer of trapped $\mathrm{e}^{-}$from the surface of semiconducting material to oxygen atom [36]. Super oxide radical anions $\left({ }^{\prime} \mathrm{O}_{2}^{-}\right)$prevent the recombination of photo-generated $\mathrm{e}^{-}$and $\mathrm{h}^{+}$. As a result of this, the rate of mineralization of adsorbed LNZ moiety on the surface of semiconducting material $5 \%$ (mole ratio) BZONPs increases under UV illumination.

(BZONPs) $\mathrm{e}^{-}+\mathrm{O}_{2} \rightarrow \mathrm{O}_{2}^{-}$

After this, ${ }^{\circ} \mathrm{O}_{2}^{-}$species interacts with $\mathrm{H}^{+}$ions to generate $\mathrm{HO}_{2}$ free radicals.

$\mathrm{O}_{2}^{-}+\mathrm{H}^{+} \rightarrow \mathrm{HO}_{2}$

$\mathrm{HO}_{2}$ free radicals may interact with photo-generated (5\%BZONPs) $\mathrm{e}^{-}$to form $\mathrm{HO}_{2}^{-}$anion.

$\mathrm{HO}_{2}+\mathrm{e}^{-} \rightarrow \mathrm{HO}_{2}^{-}$ 


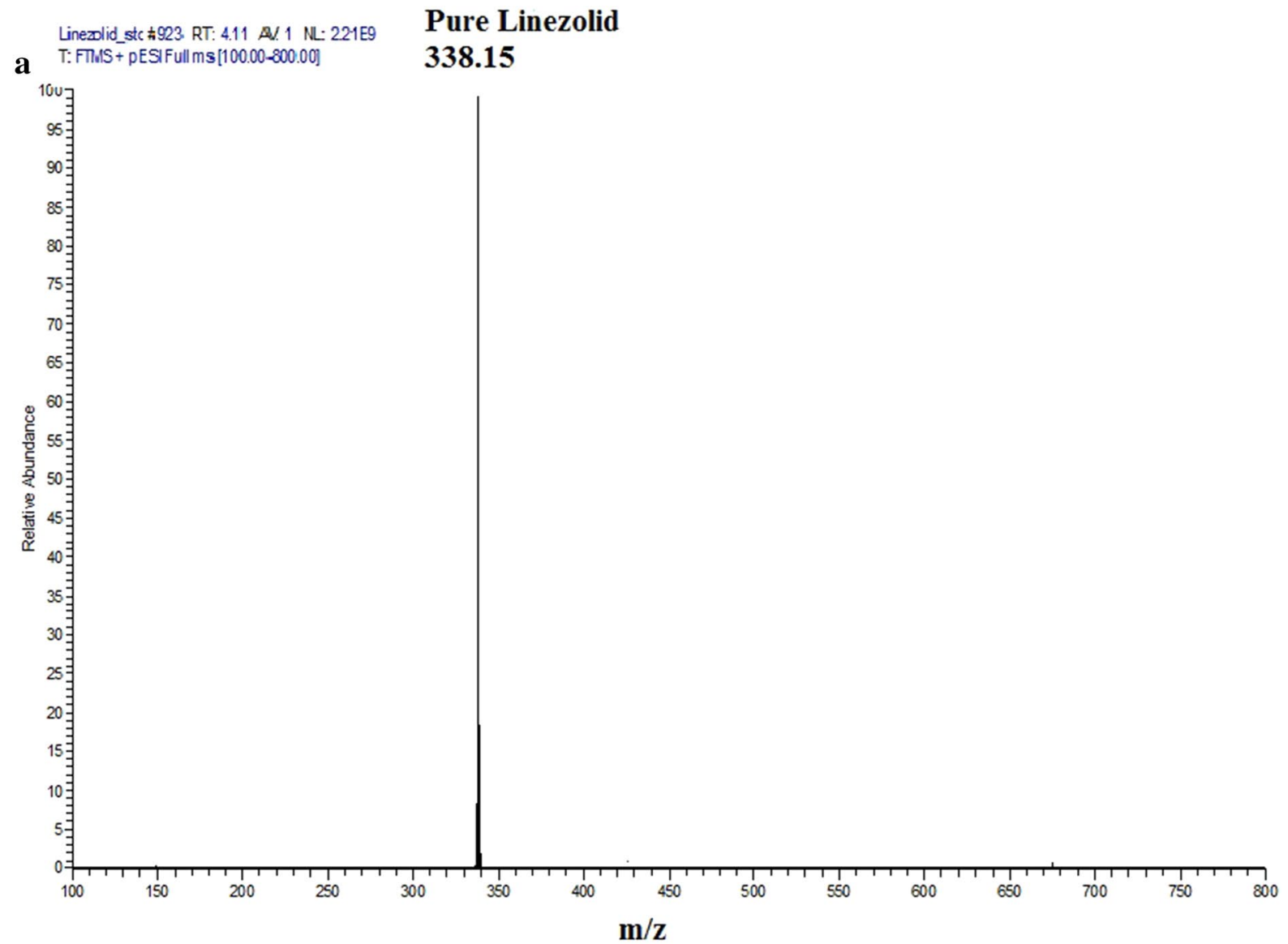

LinezolidwithUV \#101 RT: 0.45 AV: 1 NL: 1.05E 8 T: FTMS + p ESI Full ms [100.00-1500.00]

b

UV/Linezolid_P21

181.05

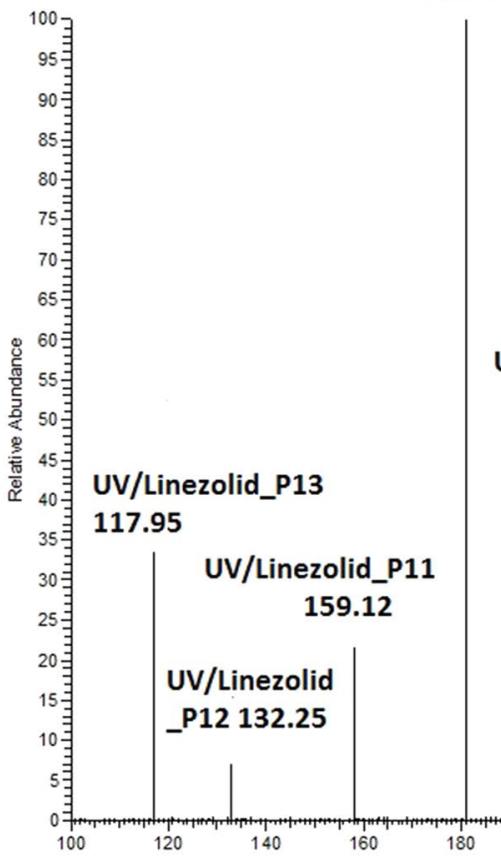

UV/Linezolid_P22

198.43

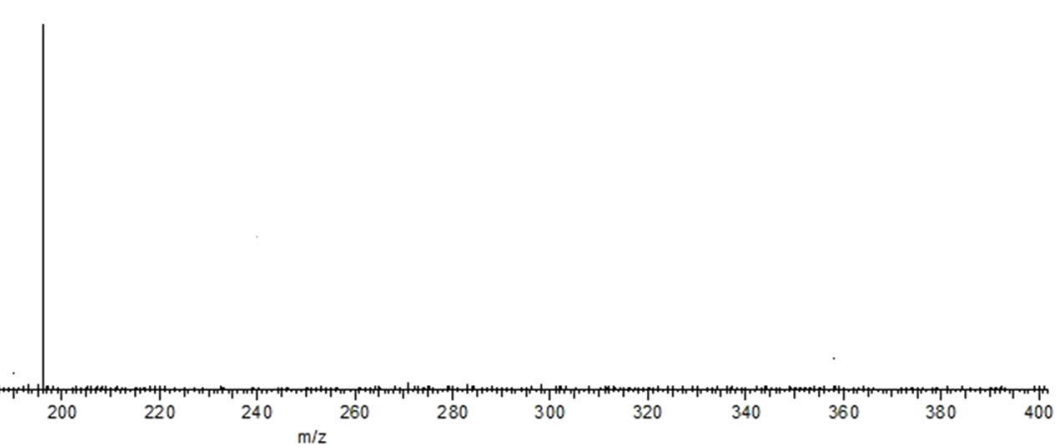

Fig. 9 HR-MS spectra of (a) Pure antibacterial drug LNZ moiety (b) Photo-degraded products of LNZ under UV illumination with its molecular ion peaks at $\mathrm{m} / \mathrm{z}$ 
Table 3 Degraded Products of LNZ with UV illumination by HR-MS analysis

\begin{tabular}{|c|c|c|c|c|c|}
\hline $\begin{array}{l}\text { Linezolid Products and } \\
\text { degraded moiety }\end{array}$ & $\begin{array}{l}\text { Measured } \\
\text { molecular ion peak } \\
\left(\mathrm{M}+\mathrm{H}^{+}\right)\end{array}$ & $\begin{array}{l}\text { Theoretical Mass of } \\
\text { products }(\mathrm{Da})\end{array}$ & $\begin{array}{l}\text { MF (molecular } \\
\text { formulae of the } \\
\text { products) }\end{array}$ & $\begin{array}{l}\text { (Measured } \\
\text { mass-theoreti- } \\
\text { cal mass) }\end{array}$ & $\begin{array}{l}\text { Name of the analyzed } \\
\text { products and degraded } \\
\text { moiety }\end{array}$ \\
\hline $\begin{array}{l}\text { Linezolid_P11 (Oxazolidi- } \\
\text { none moiety) }\end{array}$ & 159.12 & 158 & $\mathrm{C}_{6} \mathrm{H}_{10} \mathrm{O}_{3} \mathrm{~N}_{2}$ & +1.12 & $\begin{array}{l}\text { N-(2-Oxozolidin- } \\
\text { 5-ylmethyl)-acetamide }\end{array}$ \\
\hline $\begin{array}{l}\text { Linezolid_P12 (Oxazolidi- } \\
\text { none moiety) }\end{array}$ & 132.25 & 131 & $\mathrm{C}_{5} \mathrm{H}_{10} \mathrm{O}_{2} \mathrm{~N}_{2}$ & +1.25 & $\begin{array}{l}\text { 5-methylaminomethyl- } \\
\text { oxazolidin-2-one }\end{array}$ \\
\hline $\begin{array}{l}\text { Linezolid_P13 (Oxazolidi- } \\
\text { none moiety) }\end{array}$ & 117.95 & 116 & $\mathrm{C}_{4} \mathrm{H}_{8} \mathrm{O}_{2} \mathrm{~N}_{2}$ & +1.95 & $\begin{array}{l}\text { 5-Aminomethyl-oxazolidin- } \\
\text { 2-one }\end{array}$ \\
\hline $\begin{array}{l}\text { Linezolid_P21 (Morpho- } \\
\text { line and phenyl moiety) }\end{array}$ & 181.05 & 180 (Major product) & $\mathrm{C}_{10} \mathrm{H}_{11}$ NOF & +1.12 & $\begin{array}{l}\text { 4-(2-Fluro-phenyl)-mor- } \\
\text { pholine }\end{array}$ \\
\hline $\begin{array}{l}\text { Linezolid_P22 (Morpho- } \\
\text { line moiety) }\end{array}$ & 198.43 & 197 & $\mathrm{C}_{9} \mathrm{H}_{5} \mathrm{O}_{2} \mathrm{NF}$ & +1.12 & $\begin{array}{l}\text { 3-Fluoro-4-methyl-4-mor- } \\
\text { pholin-4-yl-cyclohexa- } \\
\text { 2,5-dienone }\end{array}$ \\
\hline
\end{tabular}

Then $\mathrm{HO}_{2}^{-}$anion combines with $\mathrm{H}^{+}$ions to produce $\mathrm{H}_{2} \mathrm{O}_{2}$ $[37,38]$.

$\mathrm{HO}_{2}^{-}+\mathrm{H}^{+} \rightarrow \mathrm{H}_{2} \mathrm{O}_{2}$

Subsequently, $\mathrm{H}_{2} \mathrm{O}_{2}$ interacts with (5\% BZONPs) $\mathrm{e}^{-}$at the conduction band of the semiconductor material $5 \%$ (mole ratio) BZONPs to generate ${ }^{-} \mathrm{OH}$ and ${ }^{\circ} \mathrm{OH}$ species.

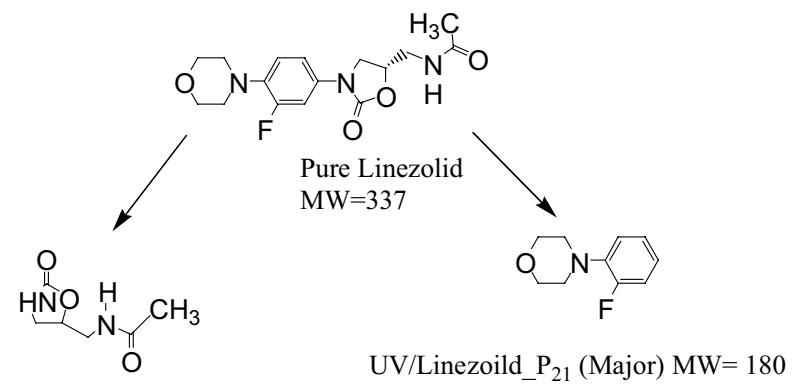

UV/Linezolid_P $\mathrm{P}_{11} \mathrm{MW}=158$
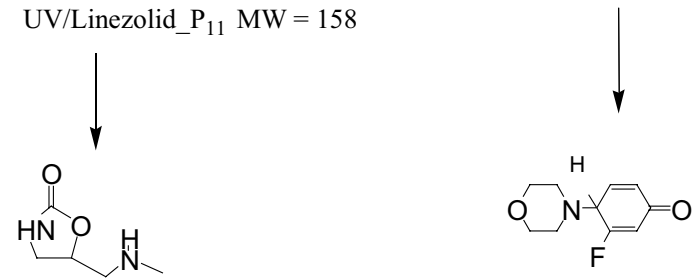

$\mathrm{UV} /$ Linezolid_P $\mathrm{P}_{12} \mathrm{MW}=131$

UV/Linezolid_P 22 MW $=197$

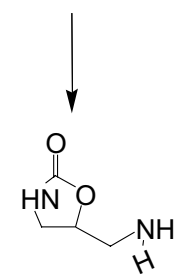

UV/Linezolid_P $\mathrm{P}_{13} \mathrm{MW}=116$

Fig. 10 Photo-degraded products of antibacterial drug LNZ under UV light
$\mathrm{H}_{2} \mathrm{O}_{2}+$ (BZONPs) $\mathrm{e}^{-} \rightarrow \mathrm{OH}^{-}+\mathrm{OH}$

These ${ }^{\circ} \mathrm{OH}$ species which are formed in above equation may remove the LNZ moiety adsorbed on the surface of semiconducting material $5 \%$ (mole ratio) BZONPs to form harmless simple substances $[11,39,40]$.

$\cdot \mathrm{OH}+\mathrm{LNZ} \rightarrow$ Photo-degraded products

Thus, LNZ moiety can be photo-degraded into harmless simple substances using semiconducting material $5 \%$ (mole ratio) BZONPs. The formation of highly reactive ${ }^{\circ} \mathrm{OH}$ species in this proposed mechanism is possible only due to dissolved oxygen and water molecules. This initiates the mineralization of adsorbed LNZ moiety on the surface of semiconducting material 5\% (mole ratio) BZONPs.

\section{Conclusion}

The semiconducting materials ZONPs and 5\% (mole ratio) BZONPs were synthesized by chemical precipitation method. The photo-degraded products of LNZ moiety under UV illumination are analyzed. The XRD pattern of ZONPs and $5 \%$ (mole ratio) BZONPs revealed that these semiconducting materials have hexagonal wurzite structure. A suitable photo-generated electron-hole pair mechanism is proposed in agreement with experimental results and HR-MS data. Average crystallite size of ZONPs and $5 \%$ (mole ratio) BZONPs were found to be $35.2( \pm 3) \mathrm{nm}$ and $24.5( \pm 2) \mathrm{nm}$ respectively which are in agreement with literature. Analysis of SEM images shows slightly increase in surface area in $5 \%$ (mole ratio) BZONPs as compared to ZONPs. Hence, the rate of degree of mineralization of LNZ by semiconducting material $5 \%$ (mole ratio) BZONPs is more than ZONPs under UV illumination. EDX of $5 \%$ (mole ratio) BZONPs shows that the mass percentage of zinc is 71.2 , oxygen is 23.9 and barium is 4.78 . Kinetic data shows that there is increase in the rate constant values 
Fig. 11 Photocatalytic degradation mechanism of LNZ with $5 \%$ (mole ratio) BZONPs

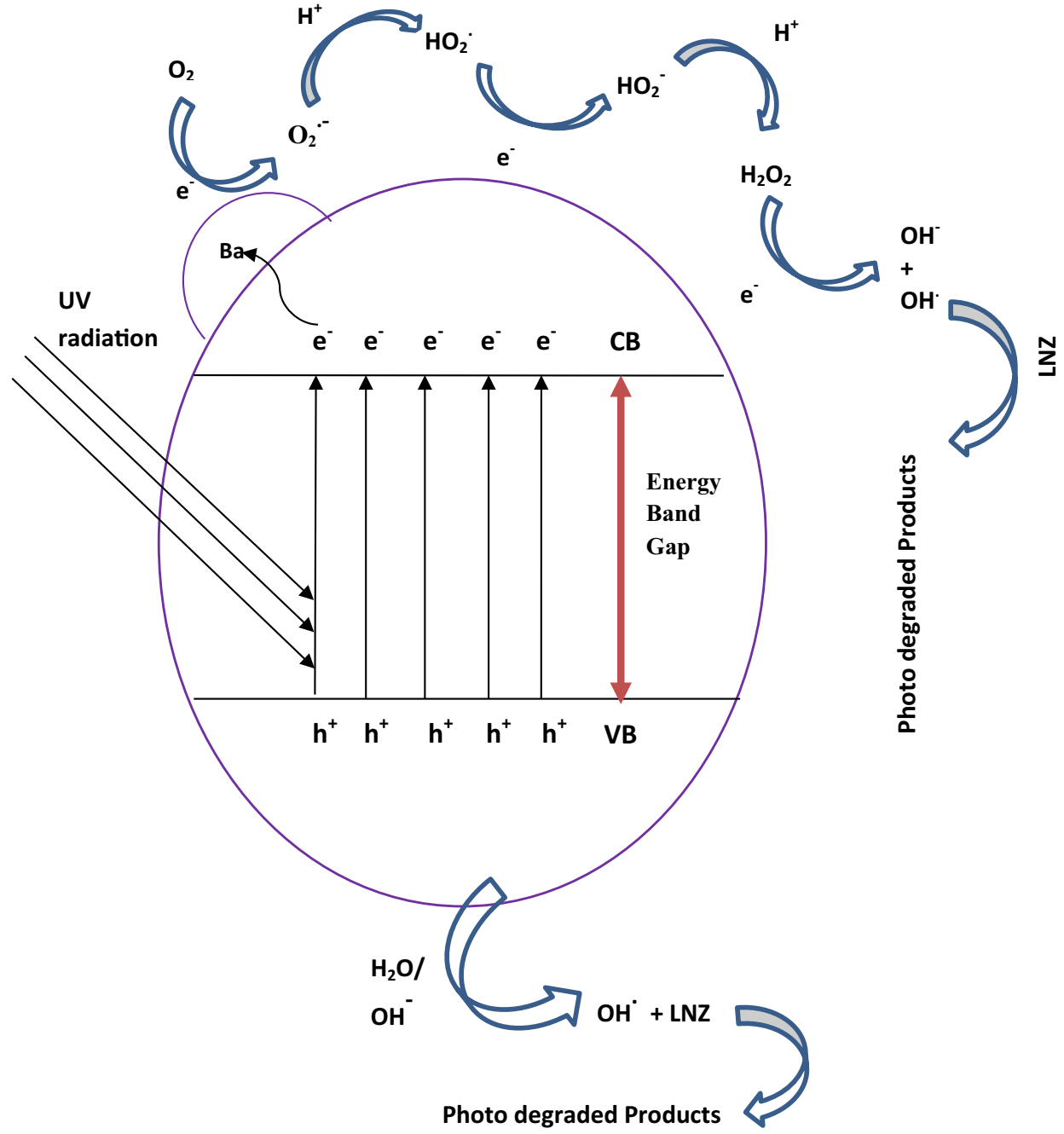

with increase in the light intensities of UV lamp. Maximum photo-degradation of antibacterial drug LNZ could be achieved in 100 min using photocatalyst semiconductor material $5 \%$ (mole ratio) BZONPs of dosage of $0.1 \mathrm{~g} \mathrm{dm}^{-3}$. Experimental results conclude that $5 \%$ (mole ratio) BZONPs is a very efficient photocatalyst for the photo degradation of LNZ present in environmental waters.

\section{Compliance with ethical standards}

Conflict of interest The authors declare that they have no conflict of interest.

\section{References}

1. Kulkarni RM, Bhamare VS, Santhakumari B (2016) Oxidative transformation of antiretroviral drug zidovudine during water treatment with permanganate: reaction kinetics and pathways. Desalin Water Treat 57:24999-25010
2. Kulkarni RM, Bhamare VS, Santhakumari B (2016) Mechanistic and spectroscopic investigations of $\mathrm{Ru}^{3+}$ catalyzed oxidative degradation of azidothymidine by heptavalent manganese at environmentally relevant $\mathrm{pH}$. Desalin Water Treat 57:28349-28362

3. Nogueira RFP, Guimaraes JR (2000) Photodegradation of dichloro acetic acid and 2, 4-dichlorophenol by ferrioxalate/ $\mathrm{H}_{2} \mathrm{O}_{2}$ system. Water Res 34:895-901

4. Lu J, Zhang T, Ma J, Chen Z (2009) Evaluation of disinfection by-products formation during chlorination and chloramination of dissolved natural organic matter fractions isolated from a filtered river water. J Hazard Mater 162:140-145

5. Zhang J, Guan X (2014) Ru (III) catalyzed permanganate oxidation of bisphenol A. Desalin Water Treat 52:4592-4601

6. Zhang J, Zhang Y, Wang H, Guan X (2014) Ru (III) catalyzed permanganate oxidation of aniline at environmentally relevant $\mathrm{pH}$. J Environ Sci 26:1395-1402

7. Zhang J, Sun B, Guan HX, Wang H, Bao LH, Huang YY (2013) Ruthenium nano particles supported on $\mathrm{CeO}_{2}$ for catalytic permanganate oxidation of butylparaben. Environ Sci Technol 47:13011-13019

8. Zhang J, Sun B, Xiong X, Gao N, Song W, Du E, Guan X, Zhou G (2014) Removal of emerging pollutants by $\mathrm{Ru} / \mathrm{TiO}_{2}$-catalyzed permanganate oxidation. Water Res 63:262-270 
9. Ligrini E, Oliveros A, Braun AM (1993) Photochemical processes for water treatment. Chem Rev 93:671-698

10. Farnetti E, Di Monte R, Jan Kaspar (2007) Homogeneous and heterogeneous catalysis in 6.100 Inorganic and bio-inorganic chemistry. Eolss Publishers, OXFORD, UK

11. Kulkarni RM, Malladi RS, Hanagadakar MS, Doddamani MR, Santhakumari B, Kulkarni SD (2016) $\mathrm{Ru}^{-\mathrm{TiO}_{2}}$ semiconducting nanoparticles for the photo-catalytic degradation of bromothymol blue. J Mater Sci: Mater Electron 27:13065-13074

12. Gaya UI, Abdullah AH (2008) Heterogeneous photocatalytic degradation of organic contaminants over titanium dioxide: a review of fundamentals, progress and problems. J Photochem Photobiol C Photochem Rev 9:1-12

13. Haque MM, Muneer $\mathrm{M}$ (2007) $\mathrm{TiO}_{2}$-mediated photocatalytic degradation of a textile derivative of a textile derivative, bromothymol blue, in aqueous suspensions. Dyes Pigm 75:443-448

14. Sakthivel S, Neppolian B, Shankar MV, Arabindoo B, Palanichamy M, Murugesan V (2003) Solar photocatalytic degradation of azo dye: comparison of photocatalytic efficiency of $\mathrm{ZnO}$ and $\mathrm{TiO}_{2}$. Sol Energy Mater Sol Cells 77:65-82

15. Comparelli R, Fanizza E, Curri ML, Cozzoli PD, Mascolo G, Agostiano A (2005) UV-induced photocatalytic degradation of azo dyes by organic capped $\mathrm{ZnO}$ nanocrystals immobilized onto substrates. Appl Catal B: Environ 62:144-149

16. Shao R, Sun L, Tang L, Chen $Z$ (2013) Preparation and characterization of magnetic core-shell $\mathrm{ZnFe}_{2} \mathrm{O}_{4} @ \mathrm{ZnO}$ nanoparticles and their application for the photo degradation of methylene blue. Chem Eng J 217:185-191

17. Misra M, Kapur P, Singla ML (2014) Surface plasmon quenched of near band edge emission and enhanced visible photocatalytic activity of Au@ZnO core-shell nanostructure. Appl Catal B: Environ 150:605-611

18. Zhang DF (2011) Photocatalytic oxidation of organic dyes with nanostructured zinc dioxide modified with silver metals. Russ J Phys Chem A 85:1416-1422

19. Kumar K, Chitkara M, Sandhu IS, Mehta D, Kumar S (2014) Photocatalytic, optical and magnetic properties of Fe-doped $\mathrm{ZnO}$ nanoparticles prepared by chemical route. J Alloys Compd 588:681-689

20. Dutta PK, Pehkonen SO, Sharma VK, Ray AK (2005) Photocatalytic oxidation of arsenic (III): evidence of hydroxylradicals. Environ Sci Technol 39:1827-1834

21. Wang R, Xin JH, Yang Y, Liu H, Xu L, Hu J (2004) The characteristics and photocatalytic activities of silver doped $\mathrm{ZnO}$ nanocrystallites. Appl Surf Sci 227:312-317

22. Barnhill AE, Brewer MT, Carlson SA (2012) Adverse effects of antimicrobials via predictable or idiosyncratic inhibition of host mitochondrial components. Antimicrob Agent Chemother 56:4046-4051

23. French $G$ (2003) Safety and tolerability of Linezolid. J Antimicrob Chemother 51:45-53

24. Landersdorfer $C B$, Bulitta JB, Kinzig M, Holzgrabe U, Sorgel $F$ (2009) Penetration of antibacterials into bone: pharmacokinetic, pharmacodynamic and bioanalytical considerations. Clin Pharmacokinet 48:89-124
25. Bhamare VS, Kulkarni RM, Santhakumari B (2018) Uncatalysed kinetic and mechanistic investigation of oxidative degradation of antibacterial drug Linezolid by heptavalent manganese at environmentally relevant $\mathrm{pH}$. IJARSE 07:706-721

26. Bukkitgar SD, Shetti NP, Kulkarni RM, Nandibewoor ST (2015) Electro-sensing base for mefenamic acid on a $5 \%$ barium-doped zinc oxide nanoparticle modified electrode and its analytical application. RSC Adv 5:104891-104899

27. Water W, Te-Hua F, Liang-Wen J, Teen-Hang M, Yin-Shing Y (2011) Surface morphology and liquid sensor sensitivity of bariumdoped ZnO thin film. J Sci Innov 1:25-32

28. Gallino F, Valentin CD, Pacchioni G, Chiesa M, Giamello E (2010) Nitrogen impurity states in polycrystalline ZnO. A combined EPR and theoretical study. J Mater Chem 20:689-697

29. Ozkan S, Kumthekar MW, Karakas G (1998) Characterization and temperature-programmed studies over $\mathrm{Pd} / \mathrm{TiO}_{2}$ catalysts for $\mathrm{NO}$ reduction with methane. Catal Today 40:3-14

30. Lin HF, Liao SC, Hung SW (2005) The dc thermal plasma synthesis of $\mathrm{ZnO}$ nanoparticles for visible-light photocatalyst. J Photochem photobiol A: Chem 174:82-87

31. Taicheng A, Yang H, Song W, Li G, Luo H, William JC (2010) Mechanistic considerations for the advanced oxidation treatment of fluroquinolone pharmaceutical compounds using $\mathrm{TiO}_{2}$ heterogeneous catalysis. J Phy Chem A 114:2569-2575

32. Sun J, Qiao L, Sun S, Wang G (2008) Photocatalytic degradation of Orange $\mathrm{G}$ on nitrogen doped $\mathrm{TiO}_{2}$ catalyst under visible light and sunlight irradiation. J Hazard Mater 155:312-319

33. Wang CC, Lee CK, Lyu MD, Juang LC (2008) Photocatalytic degradation of C. I. Basic Violet using $\mathrm{TiO}_{2}$ catalysts supported by $\mathrm{Y}$. Zeolite an investigation of the effects of operational parameters. Dyes Pigm 76:312-319

34. Peill NJ, Hoffmann MR (1998) Mathematical model of a photocatalytic fiber-optic cable reactor for heterogeneous photocatalysis. Environ Sci Technol 32:398-404

35. Konstantinou IK, Albanis TA (2004) $\mathrm{TiO}_{2}$-assisted photocatalytic degradation of azo dyes in aqueous solution: kinetic and mechanistic investigations. A review. Appl Catal B: Environ 49:1-14

36. Mahmoodi NM, Arami M, Limaee NY, Tabrizi NS (2006) Kinetics of heterogeneous photocatalytic degradation of reactive dyes in an immobilized $\mathrm{TiO}_{2}$ photocatalytic reactor. J Colloid Interface Sci 295:159-164

37. Banerjee S, Gopal J, Muraleedharan P, Tyagi AK, Raj B (2006) Physics and chemistry of photocatalytic titanium dioxide: visualization of bacterial activity using atomic force microscopy. Curr Sci 90:1378-1383

38. Baruah S, Dutta J (2009) Nanotechnology applications in pollution sensing and degradation in agriculture. Environ Chem Lett 7:191-204

39. Turchi CS, Ollis DF (1990) Photocatalytic degradation of organic water contaminants: mechanisms involving hydroxyl radical attack. J Cat 122:178-192

40. Ohko Y, Tatsuma T, Fujishima A (2001) Characterization of $\mathrm{TiO}_{2}$ photocatalysis in the gas phase as a photo electrochemical system: behavior of salt-modified system. J Phys Chem 105:10016-10021 